\title{
Ductility Behavior Fiber Reinforced Concrete Beams Strengthened With Externally Bonded Glass Fiber Reinforced Polymer Laminates
}

\author{
Mariappan Mahalingam, Ragunath Pulipakka Narashima Rao and Suguna Kannan \\ Department of Civil and Structural Engineering, Annamalai University, Chidmabaram, India
}

Received 2012-12-10, Revised 2013-02-14; Accepted 2013-03-12

\begin{abstract}
The study presents the results of an experimental investigation conducted on Steel Fiber Reinforced Concrete (SFRC) beams with externally bonded Glass Fiber Reinforced Polymer (GFRP) laminates with a view to study their strength and ductility. A total of ten beams, $150 \times 250 \mathrm{~mm}$ in cross-section were tested in the laboratory over an effective span of $2800 \mathrm{~mm}$. Three fiber reinforced concrete beams were used as reference beams. Six fiber reinforced concrete beams were provided with externally bonded GFRP laminates. One concrete beam was left virgin without any fiber reinforcement and external GFRP laminates. All the beams were tested until failure. The variables considered included volume fraction of fiber reinforcement and stiffness of GFRP laminates. The static responses of all the beams were evaluated in terms of strength, stiffness and ductility. The test results show that the beams provided with externally bonded GFRP laminates exhibit improved performance over the beams with internal fiber reinforcement.
\end{abstract}

Keywords: RC, FRC, GFRP, SFRC, Ductility

\section{INTRODUCTION}

The urgent need to strengthen concrete structures is on the rise. Various motivations lead to the increased demand for strengthening. During the past two decades, use of FRP as strengthening material on concrete structures has attracted world-wide interest in both practical applications and research. The use of Fiber Reinforced Polymers (FRP) as strengthening material has been gaining interest of many researchers for the last two decades. Various FRP materials are superior to steel in terms of resistance to electrochemical corrosion, strength to weight ratio, ease of handling and fatigue resistance. The successful use of FRP in many industries like aerospace, sports, automobiles and structural rehabilitation helped in decreasing the FRP cost. This decrease in cost, combined with savings due to the elimination of future maintenance and repair costs, makes the application of FRP economically competitive with steel.

Ductility is a structural design requirement in most design codes. In steel reinforced concrete structures, ductility is defined as the ratio of ultimate deformation to yield deformation. The most important aspect of ductility is a precaution of structural failure. Ductile structure can provide an advanced warning before failure.

Attari et al. (2008) studied the performance of reinforced concrete beams strengthening with hybrid FRP laminates. In the study, they have evaluated the contribution of the external reinforcement of concrete beams, reinforced by hybrid FRP laminates, which consist of the combination of one-way glass and carbon fibers as well as a bidirectional hybrid fabric glass carbon on their performance in term of ductility, strength and mode of failure. They concluded that the combination of the strengthening laminates GFRP and CFRP noticeably increase the ultimate load capacity and stiffness of the beams and it is an effective method to enhance their ductility.

Ceroni (2010) studied the performance of RC beams strengthened with FRP materials. He used CFRP laminates for strengthening the RC beams. He concluded that use of CFRP laminates increases the load carrying Corresponding Author: Mariappan Mahalingam, Department of Civil and Structural Engineering, Annamalai University, Chidambaram, India 
capacity but the ductility has reduced due to brittle failure caused by the occurrence of end debonding of FRP reinforcement.

Martinola et al. (2010) studied the strengthening and repair of RC beams with fiber reinforced concrete. From the experimental results, the application of a $40 \mathrm{~mm}$ thick HPFRC jacket on a RC beam provides an increase of the ultimate load. The proposed technique provides a significant structural enhancement at the serviceability limit state due to the remarkably increase of the beam stiffness under service load, the mid-span deflection can be remarkably reduced

Huanzi and Belarbi (2011) studied the ductility characteristics of fiber reinforced concrete beams reinforced with FRP rebar. They concluded that addition of polypropylene fiber has been proved to be an effective way to enhance the ductility of FRP reinforced system.

Dong et al. (2012) conducted experimental research on the fatigue and post-fatigue static behavior of reinforced concrete beams strengthened with glass or carbon fiber reinforced polymer sheets placed either vertically or obliquely. The test results have shown that externally bonded CFRP or GFRP to the lateral and bottom faces of a beam can increase the first crack load and ultimate strength greatly, arrest concrete crack extension and enhance the rigidity of strengthened beams. The CFRP strengthened beam has the highest ultimate strength but the lowest deflection and the diagonal GFRP reinforcing arrangement is more effect than the vertical arrangement in enhancing the shear strength and stiffness.

Choi et al. (2012) conducted the experimental and analytical investigation on debonding of hybrid FRPs for flexural strengthening of RC beams. One or two layers of CFRP or GFRP sheets were used for strengthening purpose. The test results shows that adding the existing three-point bending test method for a small RC beam, debonding failure can be induced in the $\mathrm{RC}$ beams strengthened with FRPs. The modifications are performed by including a saw-cut in the middle of the beam span and adding a reinforcing bar to prevent shear failure. The experimental results show that the beam strengthened with the stiffer and the thinner layers of FRPs have higher debonding strengths than the beams strengthened with less stiff and the thicker layers of FRPs. Therefore, the debonding level of the hybrid FRP plates is more influenced by the thickness of the strengthening materials than by its stiffness. The debonding strength is also influenced by the arrangement of layers and the higher debonding strengths were achieved when a layer of CFRP is attached to the concrete prior to a GFRP layer.

From the literature review, it can be found that the premature debonding of FRP laminates will affect the strength and ductility of the RC beams. Many of the researchers have concentrated only on the load carrying capacity. Some of them have recommended CFRP or GFRP sheets with two or three or more number of layers for effective strengthening. CFRP strengthened RC beams showed improved flexural strength but not ductility. It can also be found that some researchers used poly propylene fiber along with steel fibers and also they used CFRP for strengthening purpose. Using of short fibers can increase the load carrying capacity of the structural member but service life of a structural member when subjected to disaster (or) accident cannot be improved by using short fibers. Many researchers have concentred only on the flexural and shear behavior of the FRP strengthened beams.

An attempt has hence been made to provide an effective method of strengthening RC beams by introducing short steel fibers and bonding of GFRP laminates to the tension face of the beam. The main objective was is to study the ductility behavior of concrete beams with short steel fibers of different volume fractions and strengthening the FRC beams with GFRP laminates with different thickness. Three types of concrete beams were caste, conventional RC beams for reference, Dramix $\mathrm{SF}$ reinforced concrete beams with three volume fractions $(0.5,1.0$ and $1.5 \%)$ and beams with SF and UDC GFRP laminate of different thickness ( 3 and $5 \mathrm{~mm}$ ).

\section{MATERIALS AND METHODS}

All the beams were of same size as $150 \times 250 \times 3000$ $\mathrm{mm}$. The properties of steel fibers are presented in Table 1 and typical steel fiber with hooked end is shown in Fig 1. The details of tested beams and GFRP laminates used in this study are given in Table 2. All the beams were reinforced with $2 \mathrm{NoS}$ of $12 \mathrm{~mm}$ diameter bars in the tension face and two nos. of $10 \mathrm{~mm}$ diameter bars were used as hanger bars. The shear links consisted of $8 \mathrm{~mm}$ diameter two-legged stirrups @ 125 mm c/c spacing.

Table 1. Properties of Steel fibers

\begin{tabular}{ll}
\hline Steel fiber properties & \\
\hline Length & $30 \mathrm{~mm}$ \\
Shape & Hooked at ends \\
Diameter & $0.5 \mathrm{~mm}$ \\
Aspect Ratio & 60 \\
Density & $7850 \mathrm{~kg} / \mathrm{m}^{3}$ \\
Young's modulus & $210 \mathrm{MPa}$ \\
Tensile Strength & $532 \mathrm{MPa}$ \\
\hline
\end{tabular}


All the beams were tested in a $750 \mathrm{kN}$ capacity loading frame. The beams were subjected to static fourpoint bending. The loads were applied in increments of $2.5 \mathrm{kN}$. Dial gauges of $0.01 \mathrm{~mm}$ accuracy were used to measure deflections at the loading points and at midspan. A microscope of $0.02 \mathrm{~mm}$ precision was used to measure the crack width. The test set-up adopted is shown in Fig. 2.

\section{RESULTS}

The test results includes first crack load, yield load, ultimate load, deflection at ultimate load and first crack load of all the beams are given in Table 3. From the load-deflection behavior deflection ductility and energy ductility of all the beams were calculated the same is shown in Fig. 3.

\section{DISCUSSION}

The test results show that the load carrying capacity increased with increase in fiber content. The ultimate load was found to be $32 \%$ with $1.5 \%$ fiber content when compared to that of conventional concrete.

The ultimate load carrying capacity of SFRC beams with $0.5,1.0$ and $1.5 \%$ steel fibers improved by 14,20 and $32 \%$ respectively compared to the conventional $\mathrm{RC}$ beam.

From the experimental results it can also be found that the first crack load of SFRC beams with $0.5,1.0$ and $1.5 \%$ steel fibers increased by 10,20 and $36 \%$ respectively when compared to the conventional $\mathrm{RC}$ beam.

The crack width of SFRC beams with $0.5,1.0$ and $1.5 \%$ steel fibers got reduced at ultimate level by 6,16 and $29 \%$ respectively as compared to the conventional $\mathrm{RC}$ beam.
From the test results, it can also be found that the SFRC beams with GFRP laminates exhibit an increase of $93 \%$ in ultimate load capacity over the conventional RC beams and of $46 \%$ over the SFRC beams.

The fiber reinforced concrete beams with external GFRP laminates exhibit a decrease of $87 \%$ in ultimate deflection over the conventional RC beams and of $48 \%$ over the SFRC beams.

The fiber reinforced concrete beams with external GFRP laminates exhibit a decrease of $71 \%$ in crack width at ultimate load level with respect to the conventional RC beams.

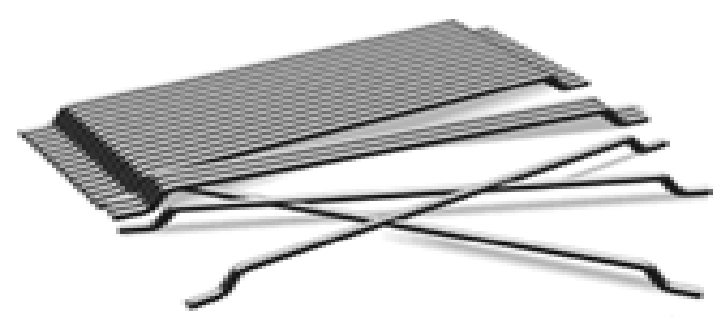

Fig. 1. Hooked end deformed fibers

Table 2. Details of beam specimens

\begin{tabular}{llll}
\hline Beam & $\begin{array}{l}\text { Volume } \\
\text { of steel } \\
\text { fiber }(\%)\end{array}$ & $\begin{array}{l}\text { GFRP } \\
\text { thickness } \\
(\mathrm{mm})\end{array}$ & $\begin{array}{l}\text { Elastic modulus } \\
\text { of GFRP) } \\
\left(\mathrm{N} / \mathrm{mm}^{2}\right.\end{array}$ \\
\hline TB0 & 0.0 & - & \\
TB1 & 0.5 & - & \\
TB2 & 1.0 & - & \\
TB3 & 1.5 & - & \\
TB11 & 0.5 & 3 & 6855.81 \\
TB12 & 0.5 & 5 & 8994.44 \\
TB21 & 1.0 & 3 & 6855.81 \\
TB22 & 1.0 & 5 & 8994.44 \\
TB31 & 1.5 & 3 & 6855.81 \\
TB32 & 1.5 & 5 & 8994.44 \\
\hline
\end{tabular}

Table 3. Test Results of beams

\begin{tabular}{lllllll}
\hline Beam & $\begin{array}{l}\text { First crack } \\
\text { load }(\mathrm{kN})\end{array}$ & $\begin{array}{l}\text { Yield } \\
\text { load }(\mathrm{kN})\end{array}$ & $\begin{array}{l}\text { Deflection at yield } \\
\text { level }(\mathrm{mm})\end{array}$ & $\begin{array}{l}\text { Ultimate } \\
\text { load }(\mathrm{kN})\end{array}$ & $\begin{array}{l}\text { Deflection at } \\
\text { ultimate level }(\mathrm{mm})\end{array}$ & $\begin{array}{l}\text { Crack } \\
\text { width }(\mathrm{mm})\end{array}$ \\
\hline TB0 & 24.53 & 34.34 & 13.15 & 47.58 & 38.85 & 0.72 \\
TB1 & 26.98 & 41.82 & 12.75 & 54.20 & 43.55 & 0.52 \\
TB2 & 29.43 & 44.15 & 12.85 & 57.14 & 51.65 & 0.50 \\
TB3 & 33.35 & 49.05 & 12.50 & 62.66 & 54.85 & 0.46 \\
TB11 & 31.88 & 53.96 & 13.50 & 73.33 & 55.35 & 0.44 \\
TB12 & 36.79 & 56.41 & 15.00 & 77.70 & 62.25 & 0.46 \\
TB21 & 36.79 & 56.41 & 14.02 & 81.42 & 68.35 & 0.42 \\
TB22 & 39.24 & 63.77 & 15.15 & 87.80 & 78.35 & 0.39 \\
TB31 & 41.69 & 63.77 & 12.40 & 86.82 & 75.95 & 0.37 \\
TB32 & 45.13 & 66.22 & 11.95 & 91.48 & 88.00 & 0.34 \\
\hline
\end{tabular}




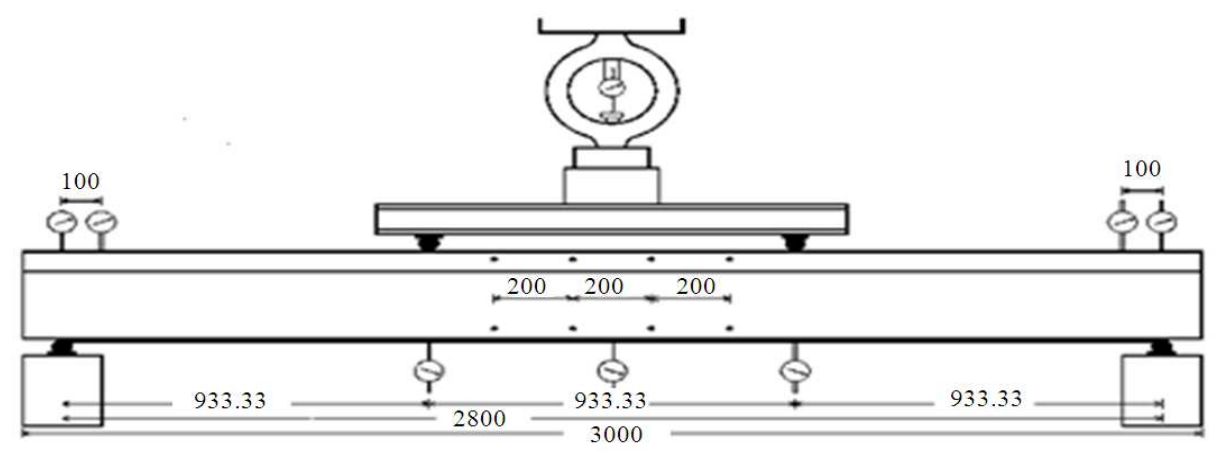

Fig. 2. Instrumentation of test set-up

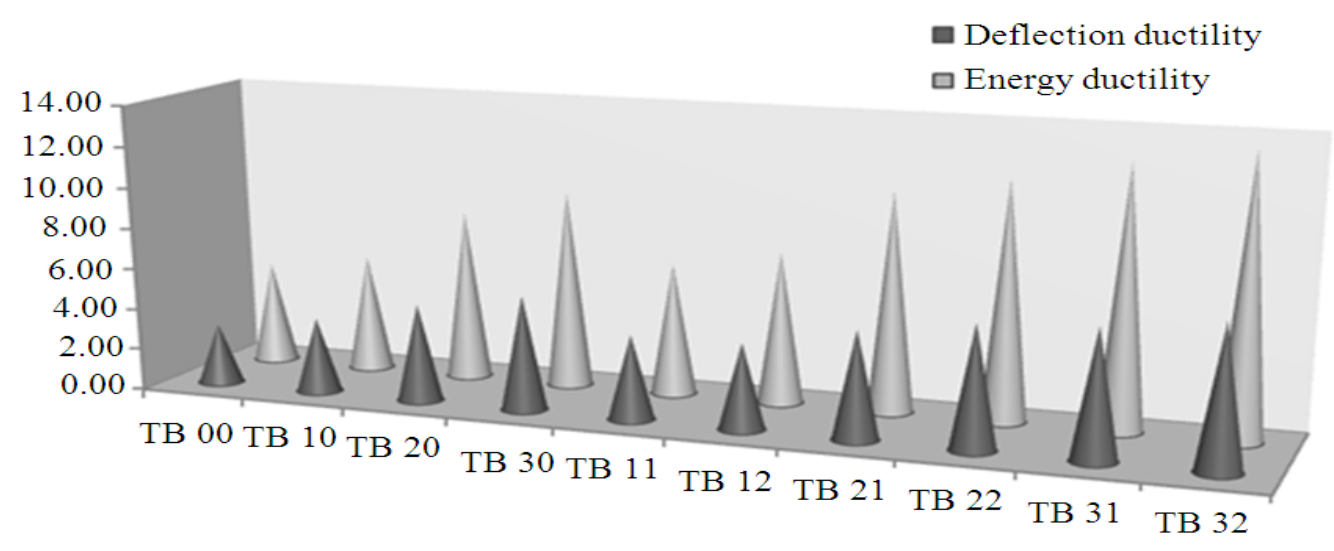

Fig. 3. Ductility Comparison of tested beams

From the test results it can also be found that deflection ductility of SFRC beams with $0.5,1.0$ and $1.5 \%$ steel fibers improved by 15,41 and $54 \%$ respectively compared to the conventional $\mathrm{RC}$ beam.

The fiber reinforced concrete beams with external GFRP laminates exhibit an increase of $133 \%$ in deflection ductility over conventional RC beams and $51 \%$ over the SFRC beams.

From the test results it can also be found that energy ductility of SFRC beams with $0.5,1.0$ and $1.5 \%$ steel fibers improved by 15, 67 and 95\% respectively compared to the conventional RC beam.

The fiber reinforced concrete beams with external GFRP laminates exhibit an increase of $40 \%$ in energy ductility over the SFRC beams.

\section{CONCLUSION}

From the test results on steel fiber reinforced concrete beams strengthened with GFRP laminates, the following conclusions are drawn:
- The SFRC beams with external GFRP laminates exhibit a maximum increase of $46 \%$ in ultimate load capacity with respect to the SFRC beams

- The SFRC beams with external GFRP laminates exhibit a decrease of deflection upto $45 \%$ with respect to the SFRC beams

- The SFRC beams with external GFRP laminates exhibit a decrease in crack width up to $42 \%$ in ultimate load capacity with respect to the SFRC beams

- The SFRC beams with external GFRP laminates exhibit an increase in deflection ductility up to $64 \%$ with respect to the SFRC beams

- The SFRC beams with external GFRP laminates exhibit an increase in energy ductility up to $40 \%$ with respect to the SFRC beams

- All the beams with GFRP laminates experienced flexural failure

- None of the beams exhibited premature failure of the laminate 


\section{REFERENCES}

Attari, N., S. Amziane and M. Chemrouk, 2008. Strengthening reinforced concrete beams using hybrid FRP laminates. Proceedings of the 4th International Conference on FRP Composites in Civil Engineering, Jul. 22-24, Zurich, Swizerland.

Ceroni, F., 2010. Experimental performances of RC beams strengthened with FRP materials. Constr. Build. Mater., 24: 1547-1559. DOI: 10.1016/j.conbuildmat.2010.03.008

Choi, E., N. Utui and H.S. Kim, 2012. Experimental and analytical investigations on debonding of hybrid FRPs for flexural strengthening of $\mathrm{RC}$ beams. Comp.: Part B., 45: 248-256. DOI: 10.1016/j.compositesb.2012.06.022
Dong, J.F., Q.Y. Wang and Z.W. Guan, 2012. Structural behavior of RC beams externally strengthened with FRP sheets under fatigue and monotonic loading. Eng. Struct., 41: 24-33. DOI: 10.1016/j.engstruct.2012.03.024

Huanzi, W. and A. Belarbi, 2011. Ductility characteristics of fiber-reinforced-concrete beams reinforced with FRP rebars. Constr. Buil. Mater., 25: 2391-2401.

DOI: 10.1016/j.conbuildmat.2010.11.040

Martinola, G., A. Meda, G.A. Plizzari and Z. Rinaldi, 2010. Strengthening and repair of RC beams with fiber reinforced concrete. Cem. Concr. Comp., 32: 731-739. DOI: 10.1016/j.cemconcomp.2010.07.001 